\title{
Genetic structure of marine and lake forms of Pacific herring Clupea pallasii
}

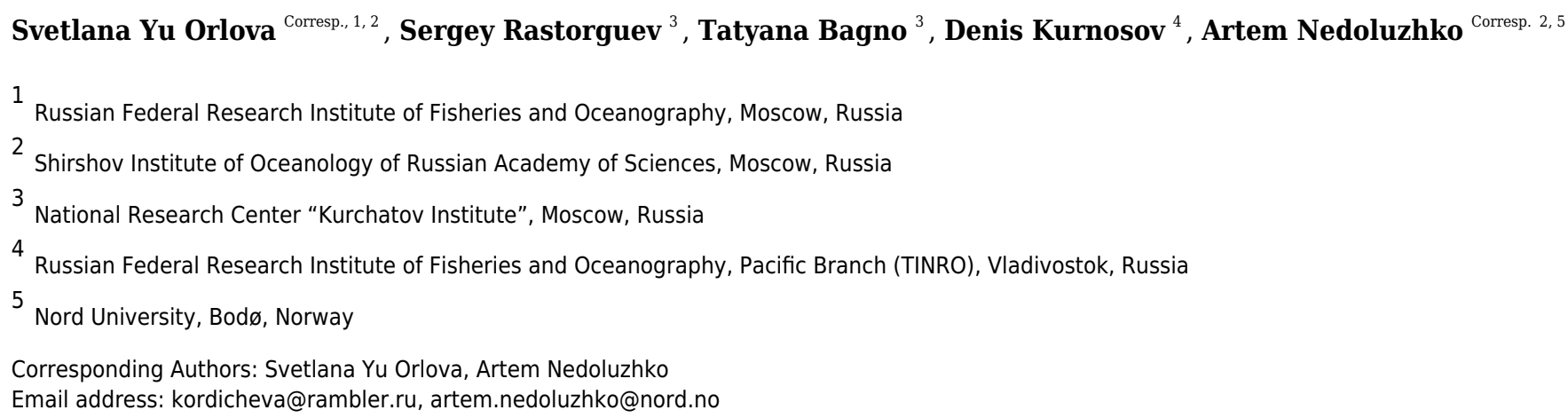

The Pacific herring (Clupea pallasii) is one of the most important species in the commercial fisheries distributed in the North Pacific Ocean and the northeastern European seas. This teleost has marine and lake ecological forms a long its distribution in the Holarctic. However, the level of genetic differentiation between these two forms is not well known. In the present study, we used ddRAD-sequencing to genotype 54 specimens from twelve wild Pacific herring populations from the Kara Sea and the Russian part of the northwestern Pacific Ocean for unveiling the genetic structure of Pacific herring. We found that the Kara Sea population is significantly distinct from Pacific Ocean populations. It was demonstrated that lake populations of Pacific herring differ from one another as well as from marine specimens. Our results show that fresh and brackish water Pacific herring, which inhabit lakes, can be distinguished as a separate lake ecological form. Moreover, we demonstrate that each observed lake Pacific herring population has its own and unique genetic legacy. 
$5 \quad{ }^{1}$ Russian Federal Research Institute of Fisheries and Oceanography, Moscow, 107140, Russia.

$6 \quad$ 2Shirshov Institute of Oceanology of Russian Academy of Sciences, Moscow, 117997, Russia

$7 \quad{ }^{3}$ National Research Center "Kurchatov Institute", Moscow, 123182, Russia

$8{ }^{4}$ Russian Federal Research Institute of Fisheries and Oceanography, Pacific Branch (TINRO),

9 Vladivostok, 690091, Russia

$10{ }^{5}$ Faculty of Biosciences and Aquaculture, Nord University, Bodø, 8049, Norway

11

12

13

14

15

16

17

18

19

20

21

22

23

24

$25 *$ Corresponding authors: Svetlana Yu. Orlova: kordicheva@rambler.ru; Artem Nedoluzhko:

26 artem.nedoluzhko@nord.no

27 


\section{Abstract}

The Pacific herring (Clupea pallasii) is one of the most important species in the commercial fisheries distributed in the North Pacific Ocean and the northeastern European seas. This teleost has marine and lake ecological forms along its distribution in the Holarctic. However, the level of genetic differentiation between these two forms is not well known. In the present study, we used ddRAD-sequencing to genotype 54 specimens from twelve wild Pacific herring populations from the Kara Sea and the Russian part of the northwestern Pacific Ocean for unveiling the genetic structure of Pacific herring. We found that the Kara Sea population is significantly distinct from Pacific Ocean populations. It was demonstrated that lake populations of Pacific herring differ from one another as well as from marine specimens.

Our results show that fresh and brackish water Pacific herring, which inhabit lakes, can be distinguished as a separate lake ecological form. Moreover, we demonstrate that each observed lake Pacific herring population has its own and unique genetic legacy.

Keywords: Pacific herring, Clupea pallasii, speciation, subspecies, ecological form, RAD sequencing, marine form, freshwater form, isolation, Russia

\section{Introduction}

The Pacific herring (Clupea pallasii) is a teleost species from the Clupeidae family and is one of the most important fishery species. It inhabits cold waters of the Pacific and Arctic oceans. The natural distribution of the species covers (i) the North-Western Pacific from the Chukchi Sea to 52 the Sea of Japan, and (ii) northeast European seas (White Sea, Pechersk Sea, and Kara Sea). Two ecological forms of Pacific herring (marine and lake) have been described to date (Andriyashev \&

54 Chernova 1995; Gritsenko 2002; Ivshina 2001; Naumenko 2001; Orlova et al. 2019). 55 Approximately twenty lake Pacific herring populations were described in the North Pacific part of 56 its distribution (Trofimov 2002). 
57 The lake ecological form of Pacific herring spawns and spends winter in brackish small bays 58 and lagoon-type lakes having direct access to the sea without any long feeding migrations (Frolov 59 1964), while the marine ecological form of herring spawns in large coastal bays, spends winter in 60 the upper part of deep-sea on the seaward border of the continental shelf, and makes long feeding 61 migrations (Naumenko 2001).

62 Previous molecular-genetic studies based on analyses of allozymes, and mitochondrial and 63 microsatellite DNA, suggest a separate genetic status of the marine and lake forms of Pacific 64 herring (Gorbachev et al. 2011; Kurnosov \& Orlova 2021; Kurnosov et al. 2016; Orlova et al. 65 2019; Rybnikova et al. 1983; Semenova et al. 2012; Semenova et al. 2018; Shimizu et al. 2018). 66 However, the status of the lake form of Pacific herring is still under debate, since the differentiation 67 between the forms was shown only on microsatellite markers (Orlova et al. 2019).

68 The restriction site-associated DNA sequencing (RAD sequencing) method (Baird et al. 2008) 69 and its modifications, such as double digestion restriction site-associated DNA (ddRAD) 70 sequencing (Peterson et al. 2012), have several advantages for large-scale evolutionary studies of non-model organisms, allowing to analyze the genomic variation of a significant number of individuals in a single sequencing run. These methods are usually used for genomics studies of non-model organisms focused on the analysis of genetic differentiation between natural populations to assess speciation (Franchini et al. 2017; Lal et al. 2016; Nedoluzhko et al. 2021; Nedoluzhko et al. 2020; Recknagel et al. 2013; Wessels et al. 2017).

In the present study, we analyzed the level of genomic diversity across wild populations of Pacific herring using the ddRAD sequencing method. Our results shed light on the genetic differentiation between lake and marine forms of this commercially important fish species. The molecular mechanisms underlying the origin of the new ecological forms in teleost species in different salinity conditions have been studied in detail (Raeymaekers et al. 2017; Rastorguev et al. 2017; Rastorguev et al. 2018; Terekhanova et al. 2019; Terekhanova et al. 2014), but key genomics and epigenomics drivers of this process remain unclear. Here, we describe genetic relationships among marine populations based on the polymorphism of a large number of SNPs by the ddRAD method and describe the population genomic structure of Pacific herring from the Kara Sea in the west to the Japan Sea in the south-east along its distribution.

\section{Material and Methods}


A total of 54 individuals from twelve wild populations of Pacific herring were collected from the Northwest Pacific and the northeastern European regions. Marine form individuals

91 (except the Kara Sea population) were sampled during the spawning period. The individuals from 92 Ainskoe Lake were also collected during the spawning period; the specimens from the lakes of 93 Kamchatka (Bolshoy Vilyuy and Nerpiche lakes) were collected during the winter period. All 94 samples were stored in the Russian Federal Research Institute of Fisheries and Oceanography 95 (VNIRO), Moscow, Russia as ethanol fixed clips of fins. The number of specimens, population 96 names, and their sources are shown in Table 1 and Figure 1. The Kara Sea is a region where Pacific 97 herring cohabit with Atlantic herring (C. harengus); therefore, specimens from this population 98 were tested using mitochondrial DNA (mtDNA) control region (D-loop) to avoid species 99 misidentification. Kara Sea specimens belonged to H2 and H7 Pacific herring haplotypes (Orlova 100 et al. 2019).

101 Genomic DNA was isolated from ethanol-preserved fins using Wizard® SV 96 Genomic 102 DNA Purification System (Promega, USA) according to the manufacturer's recommendations. 103 Purified DNA was quantified using a Qubit 2.0 fluorometer (Invitrogen, USA).

104 Fifty-four ddRAD libraries from the Pacific herring specimens (see Table 1) were 105 constructed using the method described previously by Franchini et al. (Franchini et al. 2017), and 106 using modifications described in Nedoluzhko et al. (Nedoluzhko et al. 2020). Genomic DNA was 107 digested with MspI and PstI restriction endonucleases (NEB, Ipswich, USA). Amplified ddRAD 108 libraries were quantified using a high-sensitivity chip on a 2100 Bioanalyser (Agilent, USA) and 109 sequenced on the Illumina Novaseq6000 system (Illumina, USA) using paired-end reads (150 bp 110 length). An S2 flow cell of Illumina Novaseq6000 genome analyzer (Illumina) with paired-end 111 reads $(2 \times 150$ bp length $)$ was used for ddRAD library sequencing.

\section{$112 \quad$ 2.2. Bioinformatic analyses}

113 Raw sequencing data were converted to FASTQ format with bcl2fastq2 (v2.20) and 114 underwent a quality control check using FastQC (v0.11.5: 115 https://www.bioinformatics.babraham.ac.uk/projects/fastqc/), and adapter removal using cutadapt 116 (v2.10) with the quality parameter set to 30 (Marcel 2011). Raw Illumina reads obtained from 
117 sequenced ddRAD libraries, were processed by Stacks package version 2.41 (Rochette \& Catchen 118 2017) $\square$. The clone_filter module of the Stacks, was used for PCR duplicates removal. The 119 process_radtags was used for demultiplexing the dual index reads, and for removing erroneous 120 and low-quality reads (options: $-\mathrm{c}-\mathrm{q}$ ). Clean reads were mapped to the reference genome of 121 Atlantic herring (Ch_v2.0.2) using Bowtie2 (Langmead \& Salzberg 2012) with the very-sensitive 122 parameter. The mapped data in SAM format were converted to binary (BAM) format, sorted and 123 indexed by Samtools (v1.7) (Li, 2011). SNP calling was conducted using Bcftools (v1.7) with -124 multiallelic-caller model and minimum base quality 30 (Li, 2011). The VCF file was additionally 125 filtered by the genotyping quality parameter in the vcfR package (Knaus \& Grunwald 2017).

126 Quality values were obtained using the getQUAL command. The loci with quality higher than 900 127 and with higher than 1000X coverage in all 54 Pacific herring individuals were used. The obtained $128 \mathrm{VCF}$ (filtered) file was loaded into the R statistical environment (v3.4.4) for discriminant analyses.

129 We estimated Nei's genetic distances (Nei 1978) to obtain the genetic divergence between 130 populations, which varies from 0 (no common alleles) to 1 (all the frequencies of alleles are the 131 same). The VCF file was then converted into genlight format of the adegenet R package (v2.1.3) 132 (Jombart \& Ahmed 2011), and the StaMPP R package (v1.6.1) was used to calculate fixation 133 index, Fst (AMOVA-based statistics) and Nei's genetic distances (Pembleton et al. 2013). A Fst 134 was estimated by stamppFst() function of stampp package with 10000 bootstrap replicas. We also 135 used the adegenet R package for discriminant analysis (DAPC) to determine the number of clusters 136 of genetically related individuals. Principal component analysis (PCA) was conducted using the $137 \mathrm{glPca}()$ function of the adegenet package (Jombart \& Ahmed 2011). The cluster tree topology 138 based on genetic distances between populations was visualized in iTOL (v.4) (Letunic \& Bork 139 2019).

\section{Results}

DNA sequencing statistics and Pacific herring population structure

A total of 225,858,258 Illumina reads with a length of 150 nucleotides were produced from

14554 Pacific herring specimens. The sequencing and mapping statistics for each DNA library are 146 shown in Supplementary Table 1. Initially, 1,909,252 of variable loci were found in 54 Pacific 
147 herring individuals (mean coverage $-5 \times$; mean missing data percent $-60 \%$ ). In total, 192,433

148 polymorphic loci (mean coverage $-33.6 \times$; mean missing data percent $-2.6 \%$ ) for subsequent

149

150

151

152

153

154

155

156

157

158

159

160

161

162

163

164

165

166

167

168

169

170

171

172

173

174

175

analyses remained after SNP calling and loci quality filtering.

Pairwise Fst genetic differentiation index was calculated for all studied Pacific herring populations (Table 2). P-value of the Fst estimation was equal zero for each pair population comparisons. The Fst distance between the Kara Sea population (Scvk) and other Pacific herring was the highest (ranging from 0.064 to 0.106 ), while the Pacific herring inhabiting north part of Bering Sea were more closely related to Kara Sea individuals $(F s t=0.05)$. The highest genetic distances were observed between individuals from the Kara Sea and three different lake forms, and this was independent of the geographical distance between locations. The PCA based on all SNPs also demonstrates these differences (Figure 2A).

\subsection{Genetic differentiation between lake Pacific herring populations}

Comparative analysis of the genetic differentiation between herring from lakes Bolshoy Vilyuy, Ainskoe, and Nerpiche on one side and combined marine population on the other, showed that lake form populations differ from the marine ones. The population from Bolshoy Vilyuy Lake had the highest Fst value (0.063) compared to combined marine individuals group, while the Fst value for Ainskoe and Nerpiche lakes was similar (0.041 and 0.040, respectively) (Table 2). The maximum differentiation was found between individuals from Ainskoe Lake (Sakhalin Island) and individuals from Bolshoy Vilyuy Lake and Nerpiche Lake (Kamchatka Peninsula). A lower level of differentiation was found between the two Kamchatka lakes ( $F s t=0.029)$, although this value corresponds to the Fst values between Pacific herring samples from the most remote regions (Fst value between Amur Bay and the north Bering Sea populations $=0.023$ ).

The PCA plot in Figure 2 reflects the separate position of the majority of Pacific herring populations used in our study. Figure 2A shows all populations, including samples from the Kara Sea, which significantly differs from others. In Figure 2B, for clarity, specimens from the Kara Sea are excluded from the plot, and marine and freshwater populations are highlighted by red and blue areas. Freshwater Pacific herring populations are clearly separated from marine ones.

DAPC analysis also revealed discrimination between Pacific herring populations from the Ainskoe, Bolshoy Vilyuy, and Nerpiche lakes and the Far Eastern seas (Figure 3).. Moreover, the 
176 Sakhalin population (Ainskoe Lake - Fain) differed significantly from the Eastern Kamchatka lake 177 populations (Bolshoy Vilyuy_Fvil, Nerpiche-Fner).

178 The genetic differentiation between lake populations was higher than that between marine 179 populations, except for the Kara Sea. Large genetic differences were revealed for the lake 180 populations - Nerpiche $(F s t=0.057)$, Ainskoe $(F s t=0.063)$, Bolshoy Vilyuy $(F s t=0.085)$ 181 compared to marine specimens, for which the Fst value ranged from 0.025 (Karagin Bay—Skrg) 182 to 0.036 (Gulf of Anadyr-Scva). These results demonstrate that there is significant reproductive 183 isolation between some Pacific herring lake forms and both marine and lake forms from other 184 localities.

Pacific herring from the Kara Sea population and lakes were excluded from the analysis 187 for a detailed study of the population structure of the marine form of the Pacific herring. The 188 average Fst value ranged from 0.007 to 0.036 for the Far Eastern marine populations of Pacific 189 herring. The Tugur Bay population (Sclu7) from the Sea of Okhotsk was the most genetically 190 distant population from the others (Fst index had the maximum value when compared with other 191 marine populations - $0.025-0.036$ ).

192 The greatest genetic distance was found between Pacific herring individuals from the Gulf 193 of Anadyr in the Bering Sea (Scva) and the Sea of Japan (Salex, Samur, Sukur). The individuals 194 from the Gulf of Anadyr (Scva), Karagin Bay (Skrg), Bering Sea (Sk12), and Shelikhov Gulf of 195 the Sea of Okhotsk (Seve) were genetically closely related. The individuals from the Gulf of 196 Anadyr had the highest Fst value compared to all other marine populations. Populations from the 197 Bering Sea were genetically close to the Shelikhov Gulf individuals, which presumably were 198 progenitors for the Tugur Bay population (Sclu7).

An unrooted tree of Pacific herring populations was constructed based on the Nei's distance matrix. The lake and the marine forms of Pacific herring were in separate clusters (Figure 4).

201

202

203

4. Discussion

4.1. Differentiation of the Pacific herring of the Arctic region 
204 The sampling size in this study was limited by $3-5$ specimens for one population, however, 205 as was described previously the significance of the differences between the groups depends on 206 both the number of specimens and the number of discriminating markers (Willing et al. 2012). 207 Test of significance for Fst results revealed all p-values were less than 0.0001 (Table 2).

208 We found a significant differentiation of the Kara Sea individuals from all other marine and 209 lake Pacific herring populations. Our results suggest that the Arctic Ocean populations of this 210 species were first to become separated from the others genetically. The lake populations of 211 Sakhalin Island and the Kamchatka Peninsula were subsequently isolated. This was confirmed by 212 the data from Ainskoe Lake (formed as lake 6-7.5 thousand years ago) (Budanov et al. 1957) and 213 previously published studies that Pacific herring inhabited the Russian Arctic coastline more than 214 ten thousand years ago (Grant 1986). Our previous mtDNA study did not allow us to separate 215 Arctic and Pacific Ocean populations of Pacific herring and the mass haplotypes were the same, 216 but with a reduced value of haplotypic diversity in the Kara Sea population $(\mathrm{Hd}=0.74)$ (Orlova et 217 al. 2019).

218 A decrease in haplotypic diversity in the western part of the Russian Arctic has also been shown 219 in comparison with the Pacific herring individuals of the Pacific Ocean, using a control region and 220 cytochrome b gene sequence analysis (Laakkonen et al. 2013). The low genetic differentiation 221 between individuals from the Kara and north Bering seas $(\mathrm{Fst}=0.05)$, which was described in our 222 study, may support the theory of the existence of a constant gene flow in historical terms, which 223 may be increased in response to global climate change (Vermeij \& Roopnarine 2008).

4.2. Genetic diversity of the lake form of Pacific herring

Our results demonstrated the presence of the lake form of Pacific herring, which is 226 genetically distinct from the marine form. By contrast, the previous measurements of 227 morphological traits did not find any differences (Kartavtsev et al. 2008). Nevertheless, the results 228 obtained in this study correspond to previous studies based on microsatellite and mtDNA markers 229 (Kurnosov \& Orlova 2021; Orlova et al. 2019). Furthermore, Fst values for microsatellite data 230 correlate with the same values obtained in this study. The lake forms from Ainskoe Lake and 231 Kamchatka Lake have different origins, which form a separate lake clade (Figure 4). 
232 We assume that the mechanism of reproductive isolation between marine and lake Pacific

233 herring populations is formed at the stage of spawning, and facilitates the conservation of the

234 unique lake genotypes. Different optima of water salinity during the embryo development most

235 likely provide reproductive isolation of lake forms of Pacific herring. Experiments on incubation

236 of Pacific herring embryos from a lagoon-type lake showed their successful development at a

237 salinity of 2.6\% (Gritsenko 2002), while embryos of the marine form died at a salinity below

238 4.65\% (Fridlyand 1951). Furthermore, it has been shown that embryos of Pacific herring from the

239 Sea of Okhotsk died on spawning grounds where there were desalinated by freshwater (Tyurnin

240 1965). Thus, our findings and those of previously published studies confirm the existence of a

241 separate, genetically distinct lake form of Pacific herring (Fridlyand 1951; Galkina 1960;

242 Gritsenko 2002; Tyurnin 1965). We assume the possible existence of strict natural selection as

243 well as drift post divergence barrier for freshwater alleles, which occurs at the early embryo

244 development of the lake form.

245 There are several studies that have described genome loci, or "genomic islands of 246 divergence", which are related to adaptation in plants and animals (Nosil 2012). Previously, this 247 type of natural selection of suitable freshwater alleles for these islands was considered as a way 248 for the rapid local three-spined stickleback adaptation to low-salinity environments (Terekhanova 249 et al. 2014). Three major loci with striking association to salinity have been described previously 250 in the Atlantic herring genome. These potentially adaptive loci (prolactin receptor, high 251 choriolytic enzyme, and solute carrier family 12 (sodium/chloride transporter) member 3) are 252 related to osmoregulation and embryonal development (Martinez Barrio et al. 2016). Moreover, a 253 7.8-Mb inversion on Chromosome 12 as well as 125 loci associated with adaptation for the Baltic

254 Sea conditions (including low salinity level) and 22 loci associated with different spawning times 255 were described in the chromosome-level assembly of Atlantic herring genome (Pettersson et al. 256 2019). The positive selection has also been described in SYNE2, NRXN3B, CEP128, HK3 genes 257 in both, Atlantic and Pacific herring species. Several SNPs in those genes have strong association 258 with spawn timing (Petrou et al. 2021). At the same time, it is known that the spawn timing of 259 Pacific herring, for example, in the Sea of Okhotsk, strongly depends on the ice situation and 260 significantly depending on weather conditions from year to year. (Trofimov 2006). 
261 It is likely that the origin of the Pacific herring lake form followed the sticklebacks' 262 sympatric scenario (Terekhanova et al. 2019; Terekhanova et al. 2014). Sympatric speciation is 263 usually explained by selection, where individuals/forms possess similar fitness, despite the 264 different phenotypes. This type of selection often contributes to the expansion of a subset of 265 phenotypic traits and the formation of evolutionary innovations (Hunt et al. 2011; Lahti et al. 2009; 266 Snell-Rood et al. 2010). This type of shaping is shown in various teleost species such as barbs (de 267 Graaf et al. 2010; Levin et al. 2020), Sevan trout (Levin et al. 2018), Arctic char (Alekseyev et al. 268 2002; Osinov et al. 2021), and cichlids (Barluenga et al. 2006; Kautt et al. 2020). At the same time 269 we suggest that the geographic separation and glaciation during Pleistocene does not explain our 270 findings, since the lake forms are genetically close to each other, but geographically distant. It 271 seems that adaptive divergence in freshwater and brackish populations is more reliable (Orlova et 272 al. 2019).

273 4.3. Analysis of Genetic Structure of the lake form of Pacific herring

274 Comparative genetic analysis of Pacific herring individuals from the Russian Far East showed that 275 the Pacific herring population that inhabits Tugur Bay is the most genetically distinct from both 276 marine and lake populations. The high level of genetic differentiation of this population relates to 277 its strong isolation and may be associated with adaptation to the harsh conditions in this part of the 278 Sea of Okhotsk.

279 Two large population groups can be distinguished in the North-West Pacific of the distribution of 280 Pacific herring using genomic data:

281 (1) Pacific herring of the Bering Sea, Karaginsky Bay, and the coast of the Kuril Islands;

282 (2) Pacific herring of the Sea of Japan.

283 Such genetic differences can be explained by the partial isolation of the Sea of Japan and the 284 presence of warm currents. The populations from the Sea of Japan are also distinct from each other. 285 The Amur Bay population differs significantly from Sakhalin Island's west coast population 286 (Salex), while the marine population from Sakhalin Island have an intermediate position in their 287 genetic structure between the Ainskoe Lake and Amur Bay populations (Figure 3). This indicates 288 the existence of partially separated subgroups of Pacific herring in the Sea of Japan. 


\section{Conclusions}

290 The most detailed to date investigation of the genome-wide population structure of Pacific

291 herring is presented here. The existence of a lake form of Pacific herring was confirmed based on

292 192,433 SNPs. Comparative analysis showed that the lake populations exhibit significant genetic

293 differentiation from the marine form of Pacific herring. Moreover, a high level of genetic

294 differentiation has been observed between different lake populations from Sakhalin Island and the

295 Kamchatka Peninsula. The genomic data obtained in this study are in accordance with our results

296 based on microsatellite and mtDNA markers, which confirms the formation of unique freshwater

297 Pacific herring populations in lakes.

298 The Fst data obtained enabled us to divide the Pacific herring from the North-West Pacific 299 part of its distribution into two large groups: The "North group", which inhabits the Bering Sea, 300 Kuril Islands, and the Karagin Bay; and the "South group", which inhabits coastal waters of the 301 Sea of Japan. We also found that the Sea of Japan populations significantly differ from each other 302 based on Fst values.

303 Pacific herring from the Kara Sea differ significantly from the Pacific Ocean populations 304 and lake populations (Kamchatka Peninsula and Sakhalin Islands). This indicates that the Kara 305 Sea population became separated from the Pacific Ocean part of its distribution before the lake 306 form of Pacific herring appeared.

307 Significant differences between all the studied populations, e.g. in comparing to the 308 Atlantic herring populations on both sides of the North Atlantic Ocean (Fst $\leq 0.026)$ (Lamichhaney 309 et al. 2017) suggest the existence of local populations of Pacific herring in each studied region. 310 Interestingly, the Atlantic herring in contrast to Pacific herring spawns exclusively in deep waters, 311 and seems lack reproductive isolation between fish stock in North Atlantic (Lamichhaney et al. 312 2017). In further studies, we will focus on a detailed description of these differences in frequencies 313 of "freshwater" alleles that are responsible for the freshwater adaptation of Pacific herring 314 populations, which inhabit lakes on Sakhalin Island and the Kamchatka Peninsula.

\section{5}

\section{Acknowledgments}


317 The authors greatly appreciates to A.V. Orlyuk, and I.K. Trofimov from KamchatNIRO. The

318 authors are also grateful to V.V. Gorbachev and S.V. Lipnyagov. The authors want to thank Prof.

319 A.M. Orlov and Prof. B.A. Levin for their valuable comments, and Marchenko S.L. for his help

320 during Pacific herring sampling.

321

322 Competing Interests

323 The authors declare there are no competing interests.

\section{Author Contributions}

326 Svetlana Yu. Orlova conceived and designed the experiments, performed sampling and 327 experiments, analyzed the data, prepared figures and/or tables, authored or reviewed drafts of the 328 paper, and approved the final draft.

329 Sergey M. Rastorguev analyzed the data, prepared figures and/or tables, authored or reviewed 330 drafts of the paper, and approved the final draft.

331 Tatyana A. Bagno performed the experiments, analyzed the data, prepared figures and/or tables, 332 and approved the final draft.

333 Denis E. Kurnosov performed the sampling, prepared figures and/or tables, and approved the final 334 draft.

335 Artem Nedoluzhko authored or reviewed drafts of the paper, and approved the final draft.

\section{DNA Deposition}

338 Data are available at the NCBI SRA database: SAMN18506977 - SAMN18507030. NCBI 339 accession numbers are also presented in Supplementary Table 1. 


\section{Funding}

342 This research was conducted according to VNIRO calendar plan and funded by the Federal Agency 343 for Fisheries under the State assignments No.076-00005-20-02, No.076-00005-19-01. This work 344 was carried out in Kurchatov Center for Genome Research and supported by the Ministry of 345 Science and Higher Education of Russian Federation, grant \#075-15-2019-1659. The funders had 346 no role in study design, data collection and analysis, decision to publish, or preparation of the 347 manuscript. Sergey Rastorguev was supported by the RFBR (Russian Foundation for Basic 348 Research) Grant no 19-54-54004. Nord University Open Access Fund covers the OA publication 349 costs. There was no additional external funding received for this study.

\section{Figure legends}

354 Figure 1. Map showing the different locations in Russia where Pacific herring individuals were

355 collected. Sampling locations are indicated by red squares. Blue squares indicate lake

356 populations, while red squares show marine populations.

357 Figure 2. Genetic diversity between Pacific herring populations (A) Principal component analysis 358 (PCA) plot by genotype distances for all Pacific herring populations. (B) PCA plot by genotype 359 distances for Pacific herring populations from the Pacific Ocean part of its distribution. Blue area 360 indicates lake populations, while marine populations are shown in red area.

361 Figure 3. DAPC plot (discriminant analysis of principal components) for Pacific herring 362 populations from the Pacific Ocean part of its distribution based on individual genotypes. Blue 363 area indicates lake populations, while marine populations are shown in red area.

364 Figure 4. Cluster analysis of Pacific herring performed on genome-wide identity based on Nei's 365 distances. Blue font indicates lake populations, while marine populations are shown in red. 


\section{References}

368

369

370

371

372

373

374

375

376

377

378

379

380

381

382

383

384

385

386

387

388

389

390

391

392

393

394

395

396

397

398

399

400

401

402

403

404

405

406

407

408

Alekseyev SS, Samusenok VP, Matveev AN, and Pichugin MY. 2002. Diversification, sympatric speciation, and trophic polymorphism of Arctic charr, Salvelinus alpinus complex, in Transbaikalia. Environmental Biology of Fishes 64:97-114.

Andriyashev AP, and Chernova NV. 1995. Annotated list of fishlike vertebrates and fish of the Arctic seas and adjacent waters. Journal of Ichthyology 35:81-123.

Baird NA, Etter PD, Atwood TS, Currey MC, Shiver AL, Lewis ZA, Selker EU, Cresko WA, and Johnson EA. 2008. Rapid SNP Discovery and Genetic Mapping Using Sequenced RAD Markers. PLoS One 3. 10.1371/journal.pone.0003376

Barluenga M, Stolting KN, Salzburger W, Muschick M, and Meyer A. 2006. Sympatric speciation in Nicaraguan crater lake cichlid fish. Nature 439:719-723. 10.1038/nature04325

Budanov VI, Vladimirov AT, Ionin AS, and Medvedev VS. 1957. Modern vertical movements of the sea coast in the far eas. Dokl Akad Nauk SSSR 116:829-832.

de Graaf M, Megens HJ, Samallo J, and Sibbing F. 2010. Preliminary insight into the age and origin of the Labeobarbus fish species flock from Lake Tana (Ethiopia) using the mtDNA cytochrome b gene. Molecular Phylogenetics and Evolution 54:336-343. 10.1016/j.ympev.2009.10.029

Franchini P, Parera DM, Kautt AF, and Meyer A. 2017. quaddRAD: a new high-multiplexing and PCR duplicate removal ddRAD protocol produces novel evolutionary insights in a nonradiating cichlid lineage. Molecular Ecology 26:2783-2795. 10.1111/mec.14077

Fridlyand IG. 1951. Herring reproduction near southwestern coast of Sakhalin. Izv Tikhookean Nauchno-Issled Inst Rybn Khoz Okeanogr 35:105-146.

Frolov AI. 1964. Morphological Characteristics of Herring in the Waters of Sakhalin. Izvestia TINRO 55:39-53.

Galkina LA. 1960. Reproduction and development of herring from the Sea of Okhotsk Izv Tikhookean Nauchno-Issled Inst Rybn Khoz Okeanogr 46:3-40.

Gorbachev VV, Solovenchuk LL, and Chernoivanova LA. 2011. Intraspecies structure of the Pacific herring Clupea pallasii Valenciennes, 1847 (Clupeidae: Clupeiformes) in the Sea of Japan and the southern Sea of Okhotsk, inferred from the variability of mitochondrial DNA control region. Biologiya Morya-Marine Biology 37:472-476.

Grant WS. 1986. Biochemical Genetic-Divergence between Atlantic, Clupea-Harengus, and Pacific, Clupea-Pallasi, Herring. Copeia:714-719.

Gritsenko OF. 2002. Prokhodnye ryby ostrova Sakhalin. Sistematika, ekologiya, promysel (Migratory Fish of Sakhalin Island. Systematics, Ecology, and Fishery). Moscow: Izd. VNIRO.

Hunt BG, Ometto L, Wurm Y, Shoemaker D, Yi SV, Keller L, and Goodisman MA. 2011. Relaxed selection is a precursor to the evolution of phenotypic plasticity. Proc Natl Acad Sci U S A 108:15936-15941. 10.1073/pnas.1104825108

Ivshina ER. 2001. Decline of the Sakhalin-Hokkaido herring spawning grounds near the Sakhalin coast In: Funk F, Blackburn J, Hay D, Paul AJ, Stephenson R, Toresen R, and D. W, editors. Herring 2000: Expectations for a New Millennium. Anchorage, Alaska, USA. p $245-254$.

Peerj reviewing PDF | (2021:03:59239:2:0:NEW 7 Oct 2021) 
409

410

411

412

413

414

415

416

417

418

419

420

421

422

423

424

425

426

427

428

429

430

431

432

433

434

435

436

437

438

439

440

441

442

443

444

445

446

447

448

449

450

451

452

453

454

Jombart T, and Ahmed I. 2011. adegenet 1.3-1: new tools for the analysis of genome-wide SNP data. Bioinformatics 27:3070-3071. 10.1093/bioinformatics/btr521

Kartavtsev YP, Pushnikova IG, and Rybnikova GM. 2008. Multivariate morphometric analysis of Pacific herring, Clupea pallasii (Clupeiformes: Clupeidae) in Sakhalin waters: Investigation of intraspecific differentiation. Russian Journal of Marine Biology 34:288295. 10.1134/S1063074008050040

Kautt AF, Kratochwil CF, Nater A, Machado-Schiaffino G, Olave M, Henning F, Torres-Dowdall J, Harer A, Hulsey CD, Franchini P, Pippel M, Myers EW, and Meyer A. 2020. Contrasting signatures of genomic divergence during sympatric speciation. Nature 588:106-+. $10.1038 / \mathrm{s} 41586-020-2845-0$

Knaus BJ, and Grunwald NJ. 2017. vcfr: a package to manipulate and visualize variant call format data in R. Mol Ecol Resour 17:44-53. 10.1111/1755-0998.12549

Kurnosov DS, and Orlova SY. 2021. Population Genetic Structure of Pacific Herring Clupea Pallasii in the Northwestern Pacific Ocean Based on Microsatellite Analysis. Journal of Ichthyology 61.

Kurnosov DS, Orlova SY, and Smirnova MA. 2016. Genetic variations among pacific herring (Clupea pallasii Val.) from the Okhotsk Sea and Lake Ainskoye by microsatellite loci. Izvestia TINRO 187:116-121.

Laakkonen HM, Lajus DL, Strelkov P, and Vainola R. 2013. Phylogeography of amphi-boreal fish: tracing the history of the Pacific herring Clupea pallasii in North-East European seas. BMC Evol Biol 13:67. 10.1186/1471-2148-13-67

Lahti DC, Johnson NA, Ajie BC, Otto SP, Hendry AP, Blumstein DT, Coss RG, Donohue K, and Foster SA. 2009. Relaxed selection in the wild. Trends Ecol Evol 24:487-496. 10.1016/j.tree.2009.03.010

Lal MM, Southgate PC, Jerry DR, and Zenger KR. 2016. Fishing for divergence in a sea of connectivity: The utility of ddRADseq genotyping in a marine invertebrate, the black-lip pearl oyster Pinctada margaritifera. Marine Genomics 25:57-68. 10.1016/j.margen.2015.10.010

Lamichhaney S, Fuentes-Pardo AP, Rafati N, Ryman N, McCracken GR, Bourne C, Singh R, Ruzzante DE, and Andersson L. 2017. Parallel adaptive evolution of geographically distant herring populations on both sides of the North Atlantic Ocean. Proceedings of the National Academy of Sciences of the United States of America 114:E3452-E3461. $10.1073 /$ pnas. 1617728114

Langmead B, and Salzberg SL. 2012. Fast gapped-read alignment with Bowtie 2. Nat Methods 9:357-359. 10.1038/nmeth.1923

Letunic I, and Bork P. 2019. Interactive Tree Of Life (iTOL) v4: recent updates and new developments. Nucleic Acids Res 47:W256-W259. 10.1093/nar/gkz239

Levin B, Rastorguev S, Simonov E, Boulygina E, Sharko F, Tsygankova S, Gabrielyan B, Roubenyan H, Mayden R, and Nedoluzhko A. 2018. High-throughput sequencing of the mitochondrial genomes from archived fish scales: an example of the extinct species flock of Sevan trout Salmo ischchan. Hydrobiologia 822:217-228.

Levin BA, Simonov E, Dgebuadze YY, Levina M, and Golubtsov AS. 2020. In the rivers: Multiple adaptive radiations of cyprinid fishes (Labeobarbus) in Ethiopian Highlands. Scientific Reports 10. 10.1038/s41598-020-64350-4

Marcel M. 2011. Cutadapt Removes Adapter Sequences From High-Throughput Sequencing Reads. EMBnetjournal 17:10-12. 10.14806/ej.17.1.200.

Peer] reviewing PDF | (2021:03:59239:2:0:NEW 7 Oct 2021) 
455

456

457

458

459

460

461

462

463

464

465

466

467

468

469

470

471

472

473

474

475

476

477

478

479

480

481

482

483

484

485

486

487

488

489

490

491

492

493

494

495

496

497

498

499

500

Martinez Barrio A, Lamichhaney S, Fan G, Rafati N, Pettersson M, Zhang H, Dainat J, Ekman D, Hoppner M, Jern P, Martin M, Nystedt B, Liu X, Chen W, Liang X, Shi C, Fu Y, Ma K, Zhan X, Feng C, Gustafson U, Rubin CJ, Sallman Almen M, Blass M, Casini M, Folkvord A, Laikre L, Ryman N, Ming-Yuen Lee S, Xu X, and Andersson L. 2016. The genetic basis for ecological adaptation of the Atlantic herring revealed by genome sequencing. Elife 5 . 10.7554/eLife. 12081

Naumenko NI. 2001. Biologiya i promysel morskikh seldey Dalnego Vostoka (Biology and fishing of marine herring of the Far East). Petropavlovsk-Kamchatsky: Kamchatsky Pechatniy Dvor.

Nedoluzhko AV, Sharko FS, Tsygankova SV, Boulygina ES, Ibragimova AS, Teslyuk AB, Galindo-Villegas J, and Rastorguev SM. 2021. Genomic evidence supports the introgression between two sympatric stickleback species inhabiting the White Sea basin. Heliyon 7:e06160. https://doi.org/10.1016/j.heliyon.2021.e06160

Nedoluzhko AV, Slobodova NV, Sharko F, Shalgimbayeva GM, Tsygankova SV, Boulygina ES, Jeney Z, Nguyen V, Pham TT, Nguyen DT, Volkov AA, Fernandes JMO, and Rastorguev SM. 2020. A new strain group of common carp: The genetic differences and admixture events between Cyprinus carpio breeds. Ecology and Evolution 10:5431-5439. 10.1002/ece3.6286

Nei M. 1978. Estimation of average heterozygosity and genetic distance from a small number of individuals. Genetics 89:583-590.

Nosil P. 2012. Ecological speciation. Oxford; New York: Oxford University Press.

Orlova SY, Kurnosov DS, Chikurova EA, and Shchepetov DM. 2019. Genetic Relationship between Lake and Marine Forms of Pacific Herring Clupea pallasii. Journal of Ichthyology 59:843-852. 10.1134/S0032945219060080

Osinov AG, Volkov AA, and Mugue NS. 2021. Charrs of the genus Salvelinus (Salmonidae): hybridization, phylogeny and evolution. Hydrobiologia 848:705-726.

Pembleton LW, Cogan NO, and Forster JW. 2013. StAMPP: an R package for calculation of genetic differentiation and structure of mixed-ploidy level populations. Mol Ecol Resour 13:946-952. 10.1111/1755-0998.12129

Peterson BK, Weber JN, Kay EH, Fisher HS, and Hoekstra HE. 2012. Double digest RADseq: an inexpensive method for de novo SNP discovery and genotyping in model and non-model species. PLoS One 7:e37135. 10.1371/journal.pone.0037135

Petrou EL, Fuentes-Pardo AP, Rogers LA, Orobko M, Tarpey C, Jimenez-Hidalgo I, Moss ML, Yang D, Pitcher TJ, Sandell T, Lowry D, Ruzzante DE, and Hauser L. 2021. Functional genetic diversity in an exploited marine species and its relevance to fisheries management. Proc Biol Sci 288:20202398. 10.1098/rspb.2020.2398

Pettersson ME, Rochus CM, Han F, Chen JF, Hill J, Wallerman O, Fan GY, Hong XN, Xu QW, Zhang H, Liu SS, Liu X, Haggerty L, Hunt T, Martin FJ, Flicek P, Bunikis I, Folkvord A, and Andersson L. 2019. A chromosome-level assembly of the Atlantic herring genomedetection of a supergene and other signals of selection. Genome Research 29:1919-1928. 10.1101/gr.253435.119

Raeymaekers JAM, Chaturvedi A, Hablutzel PI, Verdonck I, Hellemans B, Maes GE, De Meester L, and Volckaert FAM. 2017. Adaptive and non-adaptive divergence in a common landscape. Nature Communications 8. 10.1038/s41467-017-00256-6

Rastorguev SM, Nedoluzhko AV, Gruzdeva NM, Boulygina ES, Sharko FS, Ibragimova AS, Tsygankova SV, Artemov AV, Skryabin KG, and Prokhortchouk EB. 2017. Differential

Peer] reviewing PDF | (2021:03:59239:2:0:NEW 7 Oct 2021) 
miRNA expression in the three-spined stickleback, response to environmental changes. Sci Rep 7:18089. 10.1038/s41598-017-18128-w

Rastorguev SM, Nedoluzhko AV, Gruzdeva NM, Boulygina ES, Tsygankova SV, Oshchepkov DY, Mazur AM, Prokhortchouk EB, and Skryabin KG. 2018. Gene Expression in the Three-Spined Stickleback (Gasterosteus aculeatus) of Marine and Freshwater Ecotypes. Acta Naturae 10:66-74.

Recknagel H, Elmer KR, and Meyer A. 2013. A Hybrid Genetic Linkage Map of Two Ecologically and Morphologically Divergent Midas Cichlid Fishes (Amphilophus spp.) Obtained by Massively Parallel DNA Sequencing (ddRADSeq). G3-Genes Genomes Genetics 3:65-74. $10.1534 / \mathrm{g} 3.112 .003897$

Rochette NC, and Catchen JM. 2017. Deriving genotypes from RAD-seq short-read data using Stacks. Nature Protocols 12:2640-2659. 10.1038/nprot.2017.123

Rybnikova IG, Upryamov VE, and Pushnikova GM. 1983. Electrophoretic analysis of lake herring proteins of Sakhalin and Kamchatka. Proc Second Reg Conf of Young Scientists and Professionals "Biological Resources of Shelf: Rational Use and Protection". Vladivostok, Russia. p 63-64.

Semenova AV, Andreeva AP, Stroganov AN, Rubtsova GA, Afanasiev KI, Markevich GN, and Smirnov AA. 2012. Preliminary data on variation of four microsatellite loci in Pacific herring Clupea pallasii. Russian Journal of Genetics 48:86-92. $10.1134 / \mathrm{S} 1022795412010176$

Semenova AV, Stroganov AN, Afanasiev KI, Rubtsova GA, Zhukova KA, and Smirnov AA. 2018. Microsatellite Variability of Pacific Herring Clupea pallasii Valenciennes, 1847 from the Sea of Okhotsk and Bering Sea. Russian Journal of Genetics 54:335-345. $10.1134 / \mathrm{S} 1022795418030110$

Shimizu Y, Takahashi H, and Takayanagi S. 2018. Population structure of the Pacific herring, Clupea pallasii, around Hokkaido Island inferred on the basis of mitochondrial DNA sequences. Bulletin of the Hokkaido National Fisheries Research Institute 94:1-40.

Snell-Rood EC, Van Dyken JD, Cruickshank T, Wade MJ, and Moczek AP. 2010. Toward a population genetic framework of developmental evolution: the costs, limits, and consequences of phenotypic plasticity. Bioessays 32:71-81. 10.1002/bies.200900132

Terekhanova NV, Barmintseva AE, Kondrashov AS, Bazykin GA, and Mugue NS. 2019. Architecture of Parallel Adaptation in Ten Lacustrine Threespine Stickleback Populations from the White Sea Area. Genome Biol Evol 11:2605-2618. 10.1093/gbe/evz175

Terekhanova NV, Logacheva MD, Penin AA, Neretina TV, Barmintseva AE, Bazykin GA, Kondrashov AS, and Mugue NS. 2014. Fast evolution from precast bricks: genomics of young freshwater populations of threespine stickleback Gasterosteus aculeatus. Plos Genetics 10:e1004696. 10.1371/journal.pgen.1004696

Trofimov IK. 2002. Some problems of studies of the Pacific herring Clupea pallasii inhabiting the waters adjacent to Kamchatka. III Scientific Conference Conservation of biodiversity of Kamchatka and coastal waters. Petropavlovsk-Kamchatsky, Russia: KamchatNIRO. p 243-244.

Trofimov IK. 2006. On the influence of water temperature and salinity, and of spawning substrate quality on reproduction of Pacific herring. Izvestiya TINRO V.146:111-121.

Tyurnin BV. 1965. Reserves of herring in the Sea of Okhotsk. Izv Tikhookean Nauchno-Issled Inst Rybn Khoz Okeanogr 59:71-81. 
546 Vermeij GJ, and Roopnarine PD. 2008. Ecology. The coming Arctic invasion. Science 321:780$547 \quad 781.10 .1126 /$ science. 1160852

548 Wessels S, Krause I, Floren C, Schutz E, Beck J, and Knorr C. 2017. ddRADseq reveals 549 determinants for temperature-dependent sex reversal in Nile tilapia on LG23. BMC 550 Genomics 18. 10.1186/s12864-017-3930-0

551 Willing EM, Dreyer C, and van Oosterhout C. 2012. Estimates of genetic differentiation measured 552 by $\mathrm{F}(\mathrm{ST})$ do not necessarily require large sample sizes when using many SNP markers. PLoS One 7:e42649. 10.1371/journal.pone.0042649 


\section{Table $\mathbf{1}$ (on next page)}

Pacific herring specimens that were used in this study and their sources. 


\begin{tabular}{|c|c|c|c|c|c|c|}
\hline$\#$ & $\begin{array}{c}\text { Populatio } \\
\text { n } \\
\text { abbreviat } \\
\text { ion }\end{array}$ & $\begin{array}{l}\text { Ecological } \\
\text { form }\end{array}$ & $\begin{array}{l}\text { Sampling } \\
\text { location }\end{array}$ & $\begin{array}{l}\text { Samplin } \\
\text { g period }\end{array}$ & $\begin{array}{c}\text { Sampling } \\
\text { coordinates } \\
(\mathrm{N} ; \mathrm{E})\end{array}$ & $\begin{array}{l}\text { Number of } \\
\text { specimens }\end{array}$ \\
\hline 1 & Fvill & Lake & $\begin{array}{c}\text { Bolshoy Vilyuy } \\
\text { Lake }\end{array}$ & 2016.02 & $\begin{array}{l}52^{\circ} 49^{\prime} 25 ; \\
158^{\circ} 32^{\prime} 56\end{array}$ & 5 \\
\hline 2 & Fain & Lake & $\begin{array}{l}\text { Ainskoe Lake, } \\
\text { Sakhalin Island }\end{array}$ & 2010.06 & $\begin{array}{l}48^{\circ} 29^{\prime} 44 ; \\
142^{\circ} 3^{\prime} 12\end{array}$ & 5 \\
\hline 3 & Fnerp & Lake & $\begin{array}{l}\text { Nerpiche Lake, } \\
\text { Kamchatka }\end{array}$ & 2008.03 & $\begin{array}{l}56^{\circ} 22^{\prime} 28 ; \\
162^{\circ} 37^{\prime} 25\end{array}$ & 5 \\
\hline 4 & Seve & Marine & $\begin{array}{l}\text { Shelikhov Gulf, } \\
\text { Sea of Okhotsk }\end{array}$ & 2007.05 & $\begin{array}{l}61^{\circ} 48^{\prime} 32 \\
159^{\circ} 22^{\prime} 52\end{array}$ & 5 \\
\hline 5 & Sukur & Marine & $\begin{array}{l}\text { Kuril Islands, } \\
\text { Pacific Ocean }\end{array}$ & 2017.06 & $\begin{array}{l}44^{\circ} 14^{\prime} 55 \\
147^{\circ} 41^{\prime} 52\end{array}$ & 5 \\
\hline 6 & Samur & Marine & $\begin{array}{l}\text { Sea of Japan, } \\
\text { Amur Bay }\end{array}$ & 2017.04 & $\begin{array}{l}43^{\circ} 4^{\prime} 23 \\
131^{\circ} 42^{\prime} 5\end{array}$ & 5 \\
\hline 7 & Sk12 & Marine & Bering Sea & 2012.05 & $\begin{array}{l}61^{\circ} 23^{\prime} 46 \\
179^{\circ} 10^{\prime} 11\end{array}$ & 5 \\
\hline 8 & Skrg & Marine & $\begin{array}{l}\text { Bering Sea, } \\
\text { Karagin Bay }\end{array}$ & 2007.06 & $\begin{array}{l}58^{\circ} 36^{\prime} 6 ; \\
162^{\circ} 31^{\prime} 8\end{array}$ & 5 \\
\hline 9 & Salex & Marine & $\begin{array}{c}\text { Sea of Japan, } \\
\text { Alexandrov } \\
\text { Gulf }\end{array}$ & 2009.05 & $\begin{array}{l}50^{\circ} 57^{\prime} 0 \\
142^{\circ} 10^{\prime} 2\end{array}$ & 5 \\
\hline 10 & Scva & Marine & $\begin{array}{c}\text { Bering Sea, } \\
\text { Gulf of Anadyr }\end{array}$ & 2015.05 & $\begin{array}{l}63^{\circ} 18^{\prime} 6 ; \\
175^{\circ} 26^{\prime} 4\end{array}$ & 3 \\
\hline 11 & Sclu7 & Marine & $\begin{array}{c}\text { Sea of Okhotsk, } \\
\text { Tugur Bay }\end{array}$ & 2019.05 & $\begin{array}{l}54^{\circ} 10^{\prime} 17 \\
136^{\circ} 59^{\prime} 4\end{array}$ & 3 \\
\hline 12 & Scvk & Marine & Kara Sea & 2014.10 & $\begin{array}{l}70^{\circ} 24^{\prime} \\
65^{\circ} 37^{\prime}\end{array}$ & 3 \\
\hline
\end{tabular}




\section{Table 2(on next page)}

Table 2. Pairwise Fst values (marked by grey) and $p$-values of the comparison (above the main diagonal) for Pacific herring (Clupea pallasii) populations 


\begin{tabular}{|c|c|c|c|c|c|c|c|c|c|c|c|c|}
\hline Population & Scva & Scvk & Fain & Fnerp & Fvill & Salex & Samur & Seve & Sk12 & Skrg & Sukur & Sclu7 \\
\hline Scva & - & $<0.0001$ & $<0.0001$ & $<0.0001$ & $<0.0001$ & $<0.0001$ & $<0.0001$ & $<0.0001$ & $<0.0001$ & $<0.0001$ & $<0.0001$ & $<0.0001$ \\
\hline Scvk & 0.050 & - & $<0.0001$ & $<0.0001$ & $<0.0001$ & $<0.0001$ & $<0.0001$ & $<0.0001$ & $<0.0001$ & $<0.0001$ & $<0.0001$ & $<0.0001$ \\
\hline Fain & 0.056 & 0.093 & - & $<0.0001$ & $<0.0001$ & $<0.0001$ & $<0.0001$ & $<0.0001$ & $<0.0001$ & $<0.0001$ & $<0.0001$ & $<0.0001$ \\
\hline Fnerp & 0.046 & 0.079 & 0.040 & - & $<0.0001$ & $<0.0001$ & $<0.0001$ & $<0.0001$ & $<0.0001$ & $<0.0001$ & $<0.0001$ & $<0.0001$ \\
\hline Fvill & 0.077 & 0.106 & 0.051 & 0.029 & - & $<0.0001$ & $<0.0001$ & $<0.0001$ & $<0.0001$ & $<0.0001$ & $<0.0001$ & $<0.0001$ \\
\hline Salex & 0.028 & 0.070 & 0.031 & 0.034 & 0.058 & - & $<0.0001$ & $<0.0001$ & $<0.0001$ & $<0.0001$ & $<0.0001$ & $<0.0001$ \\
\hline Samur & 0.023 & 0.079 & 0.044 & 0.043 & 0.064 & 0.015 & - & $<0.0001$ & $<0.0001$ & $<0.0001$ & $<0.0001$ & $<0.0001$ \\
\hline Seve & 0.019 & 0.072 & 0.042 & 0.044 & 0.067 & 0.014 & 0.016 & - & $<0.0001$ & $<0.0001$ & $<0.0001$ & $<0.0001$ \\
\hline Sk12 & 0.016 & 0.073 & 0.051 & 0.052 & 0.068 & 0.025 & 0.014 & 0.010 & - & $<0.0001$ & $<0.0001$ & $<0.0001$ \\
\hline Skrg & 0.016 & 0.072 & 0.050 & 0.044 & 0.074 & 0.022 & 0.020 & 0.015 & 0.016 & - & $<0.0001$ & $<0.0001$ \\
\hline Sukur & 0.010 & 0.064 & 0.049 & 0.042 & 0.074 & 0.023 & 0.019 & 0.008 & 0.009 & 0.007 & - & $<0.0001$ \\
\hline Sclu7 & 0.036 & 0.082 & 0.063 & 0.057 & 0.085 & 0.034 & 0.032 & 0.028 & 0.028 & 0.025 & 0.032 & - \\
\hline
\end{tabular}

1

2 
Figure 1

Map showing the different locations in Russia where Pacific herring individuals were collected. Sampling locations are indicated by red squares. Blue squares indicate lake populations, while red squares show marine populations. 


\section{Chukchi Sea}

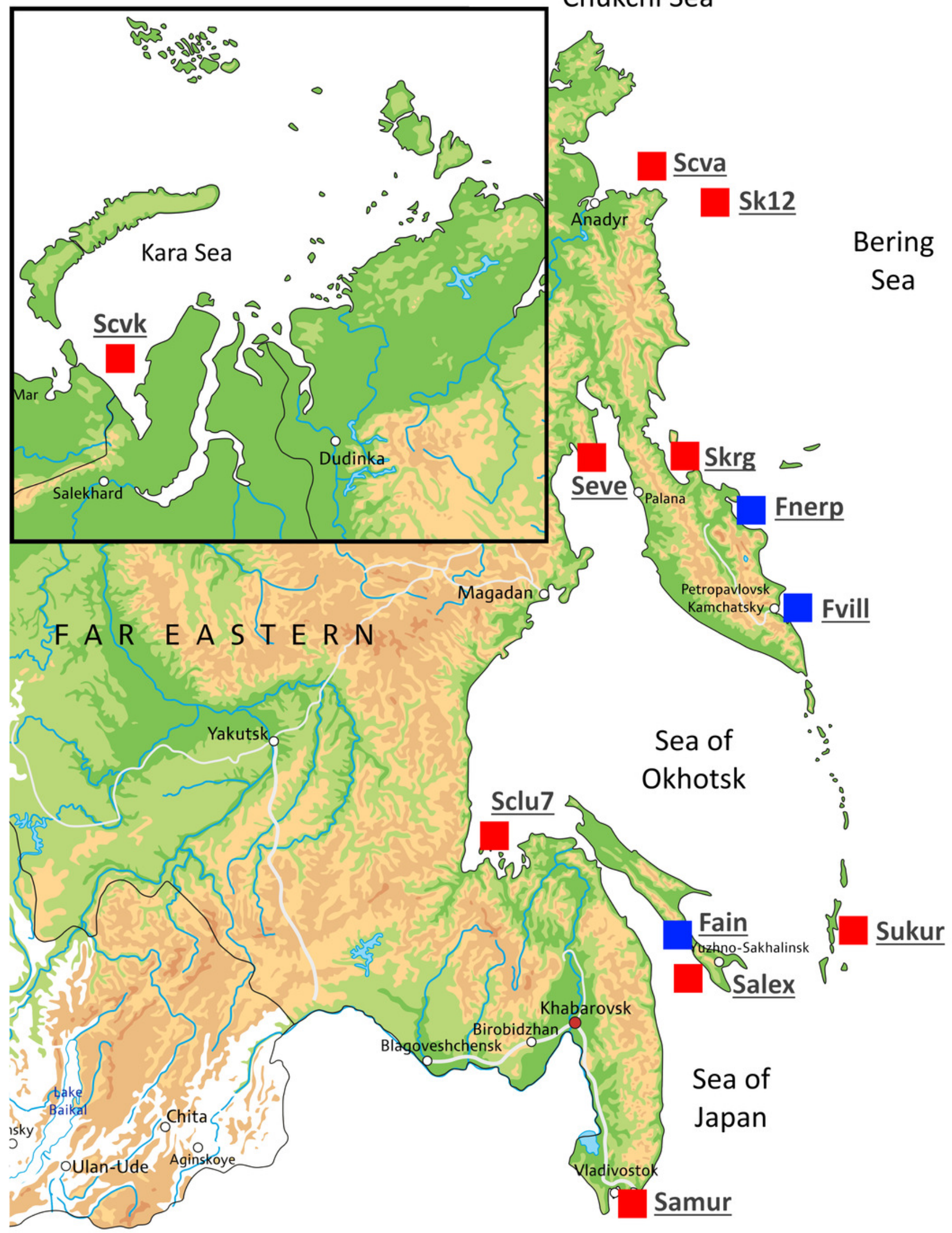


Figure 2

Genetic diversity between Pacific herring populations

(A) Principal component analysis (PCA) plot by genotype distances for all Pacific herring populations. (B) PCA plot by genotype distances for Pacific herring populations from the Pacific Ocean part of its distribution. Blue area indicates lake populations, while marine populations are shown in red area.
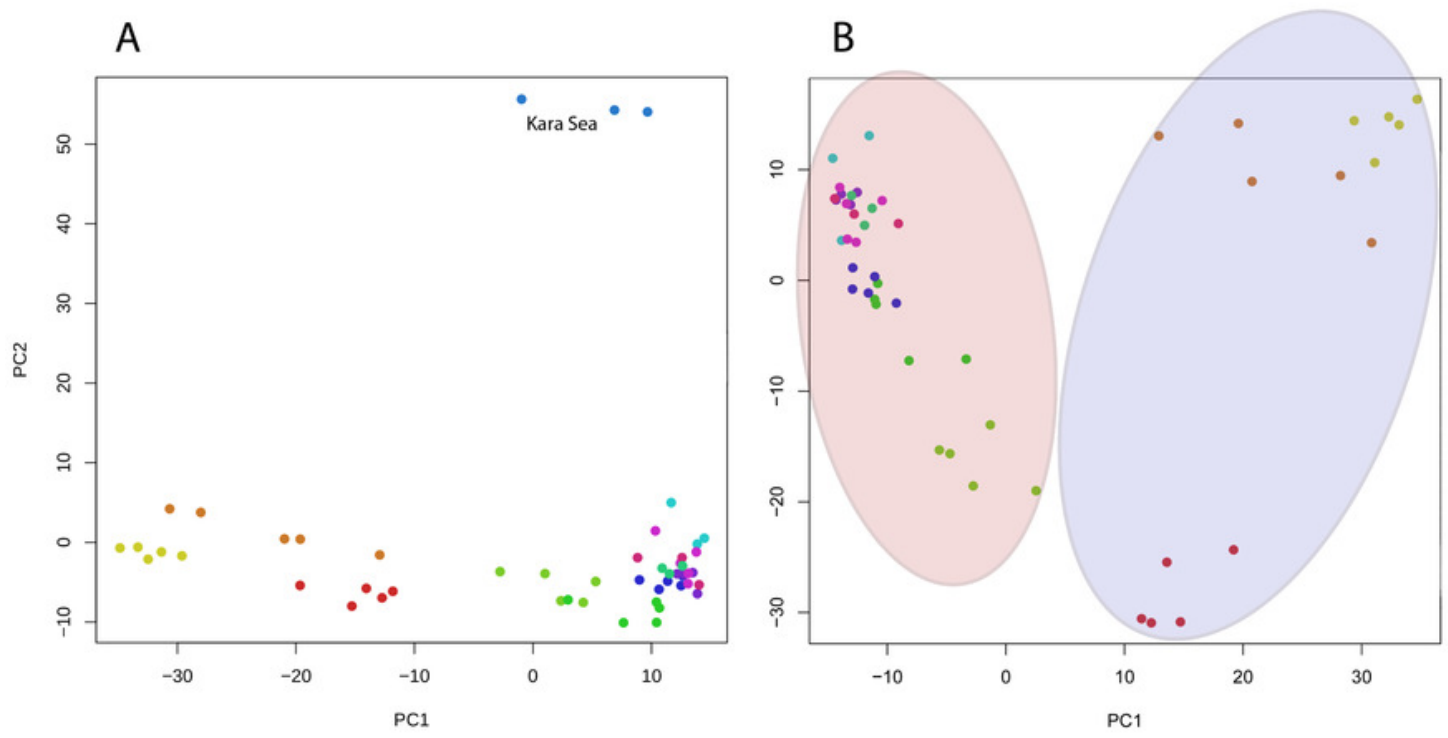

population

- Fain (Ainskoe Lake, Sakhalin Island)

- Fnerp (Nerpiche Lake, Kamchatka)

- Fvill (Bolshoy Vilyuy Lake, Kamchatka)

- Salex (Sea of Japan, Alexandrov Gulf)

- Samur (Sea of Japan, Amur Bay)

- Sclu7 (Sea of Okhotsk, Tugur Bay)

- Scva (Bering Sea, Gulf of Anadyr)

- Seve (Shelikhov Gulf, Sea of Okhotsk)

- Sk12 (Bering Sea)

- Skrg (Bering Sea, Karagin Bay)

- Scvk (Kara Sea)

- Sukur (Kuril Islands, Pacific Ocean) 
Figure 3

DAPC plot (discriminant analysis of principal components) for Pacific herring populations from the Pacific Ocean part of its distribution based on individual genotypes.

Blue area indicates lake populations, while marine populations are shown in red area

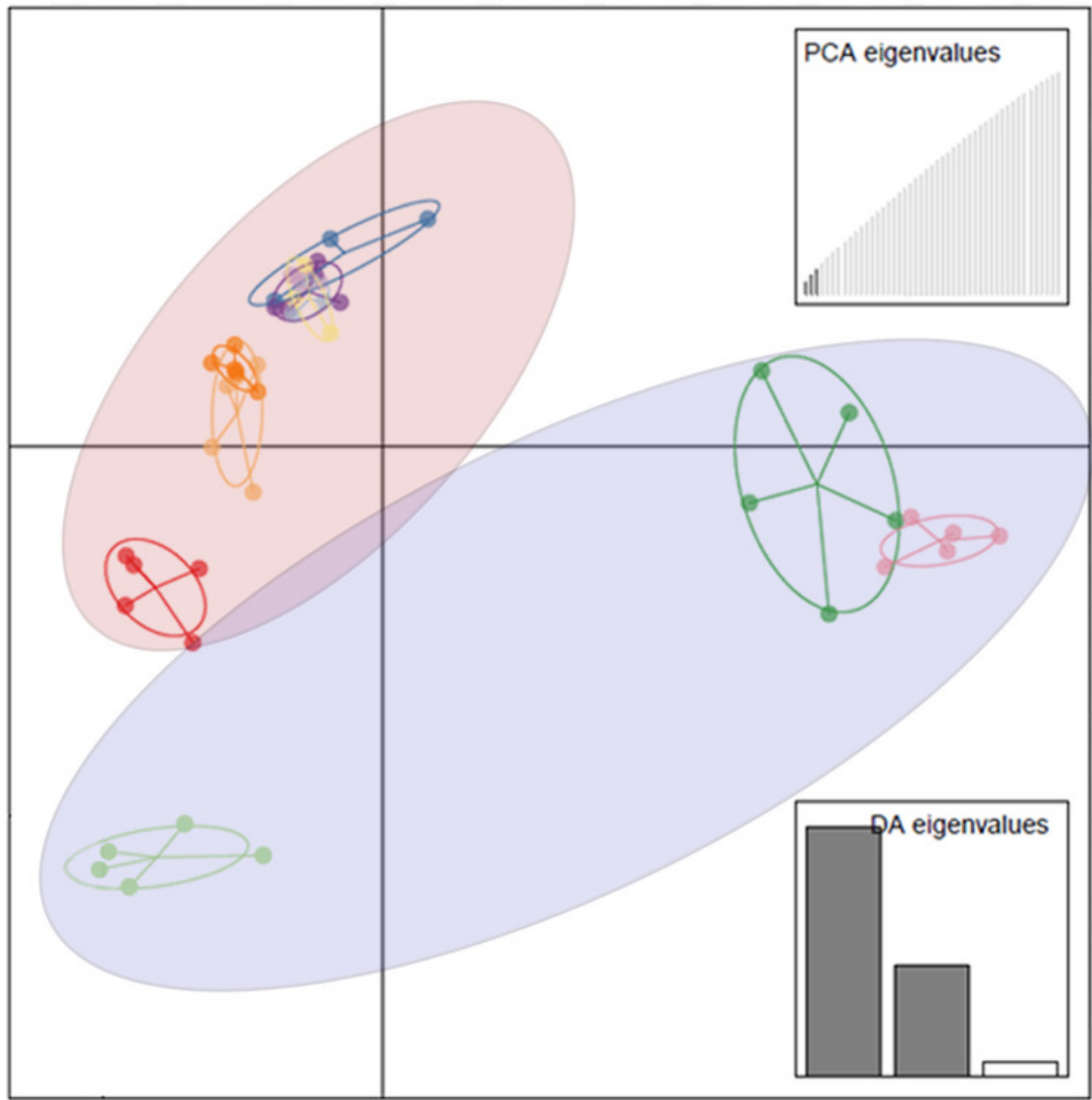

population

- Sclu7 (Sea of Okhotsk, Tugur Bay)

- Scva (Bering Sea, Gulf of Anadyr)

- Fain (Ainskoe Lake, Sakhalin Island)

- Fnerp (Nerpiche Lake, Kamchatka)

- Fvill (Bolshoy Vilyuy Lake, Kamchatka)

- Salex (Sea of Japan, Alexandrov Gulf)

- Samur (Sea of Japan, Amur Bay)

- Seve (Shelikhov Gulf, Sea of Okhotsk)

- Sk12 (Bering Sea)

- Skrg (Bering Sea, Karagin Bay)

Sukur (Kuril Islands, Pacific Ocean) 
Figure 4

Cluster analysis of Pacific herring performed on genome-wide identity based on Nei's distances. Blue font indicates lake populations, while marine populations are shown in red.

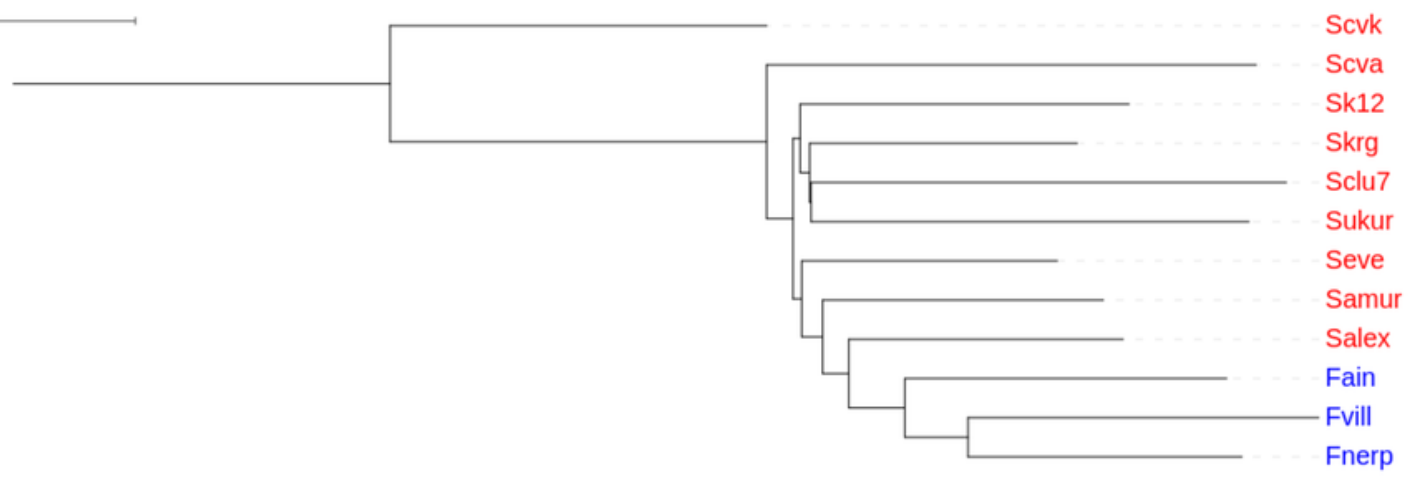

